\title{
Selective Cognitive Impairments Associated with NMDA Receptor Blockade in Humans
}

\author{
Laura M Rowland*, , Robert S Astur ${ }^{2}$, Rex E Jung ${ }^{3}$, Juan R Bustillo ${ }^{4,5}$, John Lauriello,5 and Ronald A Yeo ${ }^{6}$ \\ 'Maryland Psychiatric Research Center, University of Maryland School of Medicine, Baltimore, MD, USA; ${ }^{2}$ Department of Psychiatry, Yale \\ University, USA; ${ }^{3}$ Department of Neurology, University of New Mexico, USA; ${ }^{4}$ Department of Neurosciences, University of New Mexico, USA; \\ ${ }^{5}$ Department of Psychiatry, University of New Mexico, USA; ${ }^{6}$ Department of Psychology, University of New Mexico, USA
}

\begin{abstract}
Hypofunction of the N-methyl-D-aspartate receptor (NMDAR) may be involved in the pathophysiology of schizophrenia. NMDAR antagonists like ketamine induce schizophrenia-like features in humans. In rodent studies, NMDAR antagonism impairs learning by disrupting long-term potentiation (LTP) in the hippocampus. This study investigated the effects of ketamine on spatial learning (acquisition) vs retrieval in a virtual Morris water task in humans. Verbal fluency, working memory, and learning and memory of verbal information were also assessed. Healthy human subjects participated in this double-blinded, placebo-controlled study. On two separate occasions, ketamine/placebo was administered and cognitive tasks were assessed in association with behavioral ratings. Ketamine impaired learning of spatial and verbal information but retrieval of information learned prior to drug administration was preserved. Schizophrenia-like symptoms were significantly related to spatial and verbal learning performance. Ketamine did not significantly impair attention, verbal fluency, or verbal working memory task performance. Spatial working memory was slightly impaired. In conclusion, these results provide evidence for ketamine's differential impairment of verbal and spatial learning vs retrieval. By using the Morris water task, which is hippocampal-dependent, this study helps bridge the gap between nonhuman animal and human NMDAR antagonism research. Impaired cognition is a core feature of schizophrenia. A better understanding of NMDA antagonism, its physiological and cognitive consequences, may provide improved models of psychosis and cognitive therapeutics.

Neuropsychopharmacology (2005) 30, 633-639, advance online publication, 12 January 2005; doi: I 0.1 038/sj.npp. 1300642
\end{abstract}

Keywords: ketamine; NMDA receptor; schizophrenia; spatial navigation; learning; memory; Morris water maze

\section{INTRODUCTION}

Glutamate dysfunction, specifically hypofunction at the $\mathrm{N}$-methyl-D-aspartate receptor (NMDAR), may be involved in the pathophysiology of schizophrenia (Coyle et al, 2003; Krystal et al, 2003; Olney and Farber 1995). NMDAR antagonists, such as phencylidine (PCP) and ketamine, induce schizophrenia-like features (ie positive, negative, and cognitive symptoms) in healthy humans (Krystal et al, 1994; Newcomer et al, 1999) and exacerbate symptoms in patients with schizophrenia (Lahti et al, 1995a, b; Malhotra et al, 1997). The NMDAR has also been the focus of much research investigating learning and memory. NMDAR hypofunction appears to disrupt learning and memory (for a review, see Newcomer and Krystal, 2001) in a specific

\footnotetext{
*Correspondence: Dr LM Rowland, Maryland Psychiatric Research Center, University of Maryland School of Medicine, PO Box 21247, Baltimore, MD 21228, USA, Tel: 410402 6803, Fax: 4104026077 , E-mail: Irowland@mprc.umaryland.edu

Received 9 July 2004; revised 19 October 2004; accepted 10 November 2004

Online publication: 12 November 2004 at http://www.acnp.org/citations/ NPP I I 1 204040320/default.pdf
}

way consistent with learning and memory deficits observed in schizophrenia (Holthausen et al, 2003; Saykin et al, 1991).

Animal studies suggest that NMDAR antagonism impairs the acquisition of information by disrupting long-term potentiation (LTP) in the hippocampus (for a review, see Morris and Davis 1994). Human research suggests that NMDAR antagonism may selectively impair encoding (ie learning) of nonspatial information, but not retrieval of nonspatial information already learned (Hetem et al, 2000; Krystal et al, 2000). However, these studies only partially characterize the differential effects of NMDAR antagonism on encoding and retrieval of information in humans.

One major aim of this study was to investigate the effects of a noncompetitive NMDAR antagonist, ketamine, on spatial learning and memory in a virtual Morris water task in humans (Astur et al, 1998). This task was modeled after the Morris water maze that assesses spatial learning and memory in rodents and is often regarded as the 'gold standard' in testing hippocampal function (Morris, 1981). Several studies have shown that humans use similar spatial strategies as rodents to solve this task (Astur et al, 1998; Hamilton et al, 2002; Sandstrom et al, 1998). Additionally, 
we have shown that this task is sensitive to hippocampal damage in humans in a manner that is similar to the impairments seen following hippocampal damage in rodents (Astur et al, 2002).

Consistent with prior research, we investigated the effects of ketamine on learning and memory of verbal information, working memory, attention, and verbal fluency. We hypothesized that ketamine would disrupt learning of verbal and spatial information but not retrieval of previously acquired information. Moreover, we hypothesized that the impairment in learning would be positively correlated with schizophrenia-like symptoms induced by ketamine.

\section{METHOD}

\section{Course of Events}

This study was double-blind, placebo-controlled, and conducted over two sessions separated by 1-2weeks. Each session consisted of placebo/ketamine administration, magnetic resonance spectroscopy (MRS) scanning (Rowland et al, 2005), behavioral ratings, and cognitive assessments, respectively. Behavioral ratings were conducted approximately $30 \mathrm{~min}$, and cognitive testing commenced approximately $45 \mathrm{~min}$ following drug administration start when drug levels have been shown to be at steady state with this protocol (Newcomer et al, 1999). Each subject was administered ketamine on one day and placebo on another in a block randomized manner.

\section{Subjects}

A total of 10 healthy, male subjects completed this study (mean age $=24.7$ years; standard deviations $(\mathrm{SD})=3.4$ ) Inclusion/exclusion criteria were: (1) no past or present psychiatric disorder as determined with the Structured Clinical Interview for DSM-IV, Non-Patient Version (SCIDNP; First et al, 1995), (2) no first-degree relatives with a diagnosis of a psychotic disorder, (3) no current medical illnesses as determined with a physical exam and laboratory tests, (4) no previous exposure to ketamine or PCP. All subjects gave written informed consent prior to the study and were paid for their participation. This study was approved by the University of New Mexico Human Research Review Committee and the United States Food and Drug Administration.

\section{Drug Administration}

Ketamine was administered with a loading dose of $0.27 \mathrm{mg} /$ $\mathrm{kg}$ over $10 \mathrm{~min}$ and a maintenance dose of $0.00225 \mathrm{mg} / \mathrm{kg} /$ min for the remaining extent of the experiment (Newcomer et al, 1999). This dose is well below that used for anesthesia and has proven reliable in producing mild schizophrenialike symptoms with an excellent safety profile (Newcomer et al, 1999). Placebo was saline administered in a similar manner as ketamine. Blood pressure, heart rate, and oxygen saturation were monitored continuously by a licensed nurse and physician. Subjects were discharged and allowed to leave the study premises only after they were proven to be fully alert and oriented, ambulating freely, and completely symptom-free (ie all symptom rating scores and all vital signs were back to baseline). Subjects were not allowed to drive to or from the study. To ensure that there were no residual adverse effects or recreational substance use with ketamine-like drugs, subjects were contacted by phone the evening of study participation, as well as 1 week, 1 month, and 3 months following study participation.

\section{Behavioral Assessments}

Ratings were obtained by one psychiatrist (JB) with the Brief Rating Psychiatric Rating Scale (BPRS; Overall and Gorham, 1962), the Scale for the Assessment of Negative Symptoms (SANS; Andreasen, 1984), and the Clinician Administered Dissociative States Scale (CADSS; Bremner et al, 1998).

Learning and memory. To assess acquisition and retrieval of spatial information, subjects performed three different versions of a virtual Morris water task (Astur et al, 1998). Each version was distinct in its cues and dimensions. Details of this task have been presented previously (Astur et al, 1998, 2002, 2003). The first water task version was learned prior to the experimental sessions, and was used to assess retrieval. The second and third versions of the tasks were learned during the experimental sessions and were used to assess acquisition. The tasks consisted of a virtual room containing a round pool conceptually split into four quadrants with a platform hidden in one of the quadrants and four starting points. See Figure 1 for illustration.
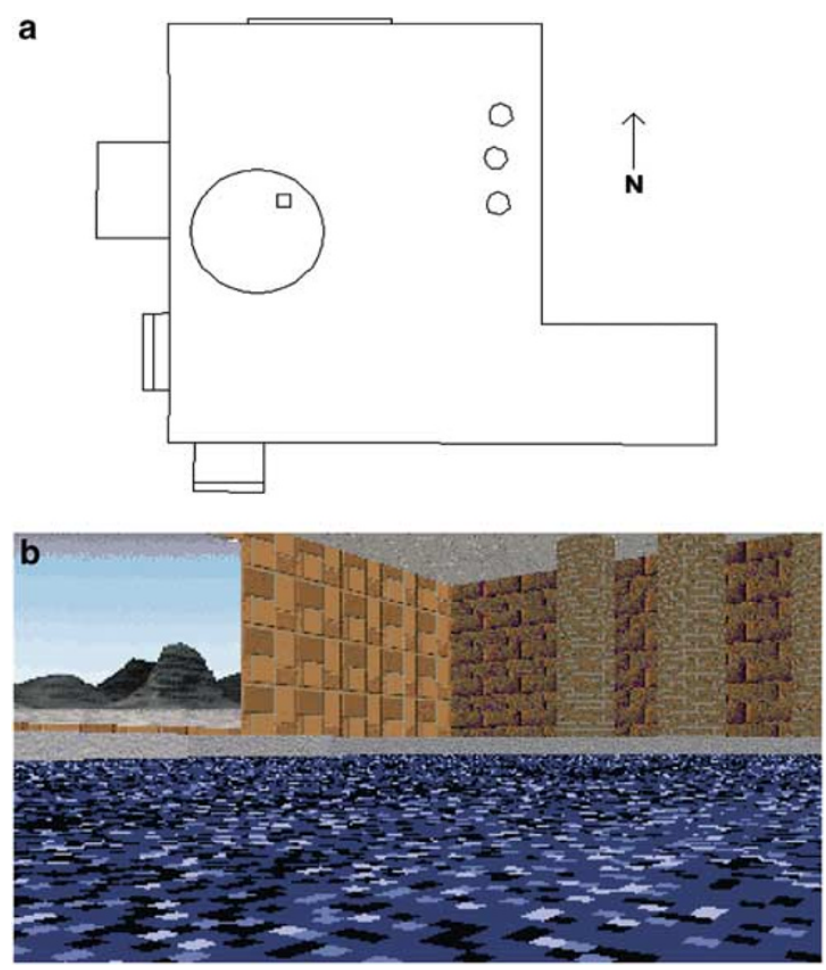

Figure I (a) Aerial view of the room and pool. The platform is in the location it would be during a hidden platform trial (ie the northeast quadrant). (b) A view within the pool. The participant is facing the northeast corner. 
Participants were told that they would be in a pool filled with water and that the goal was to escape from the water as quickly as possible. This was accomplished by swimming to the hidden platform as quickly as possible. Participants used a joystick to navigate through the pool starting from one of four possible starting points. If the subject moved over the region of the pool where the platform was hidden the platform rose out of the water and the message 'Congratulations. You have escaped from the water' appeared on the computer screen. If the platform was not located within $60 \mathrm{~s}$, the platform rose from beneath the surface of the water so that it was visible, and the message 'Please swim to the red platform' appeared on the screen. At that point, the subject had to swim to the visible platform to complete the trial.

The task consisted of five blocks of four trials totaling 20 trials. The starting point was block randomized. The hidden platform remained in the same location for all 20 trials: this was not revealed to the subjects. Distance traveled and escape latency to the platform were measured. After the 20 trials, a $45 \mathrm{~s}$ probe trial was administered. For the probe trial, the platform was removed unbeknown to the participant, and the participant was allowed to search for the platform. The distance traveled in the platform quadrant was measured as an indicator of spatial memory. Following the probe trial, two blocks of four visible platform trials were administered. These trials were identical to the hidden platform trials except that the platform was raised visibly out of the water. This was used as a control for attention, motivational, and motor processes.

Acquisition and retrieval of verbal information were assessed with the Hopkins Verbal Learning Test (HVLT; Lezak, 1995). Three lists of 12 words were administered to the participants. These lists have been proven to be comparable in recognition and retrieval performance (Lezak, 1995; pp 448). One list was learned prior to the experimental sessions and was used to assess retrieval. The other two lists were administered during the experimental sessions and were used to assess acquisition. For this task, the examiner read the words aloud at a $1 \mathrm{~s}$ per word pace, after which the participant was asked to recall as many words as possible. For learning the list prior to the experimental sessions, this procedure was repeated until the participant could repeat the list two consecutive times. For the test of retrieval of this list, the participant was asked to recall as many words as possible during both experimental sessions. For acquisition, this procedure was repeated two more times totaling three trials. Delayed recall was assessed $30 \mathrm{~min}$ later.

Attention. Attention was assessed with the Stroop ColorWord Interference Test (Lezak, 1995). This task consisted of three timed trials lasting $45 \mathrm{~s}$. For this task, participants (1) read as many color words in black ink as possible; (2) named as many color patches as possible; and (3) named the ink color of different colored words.

Working memory. Verbal and spatial working memory were assessed with forward and backward digit span and spatial spans (from Wechsler Memory Scale III; Lezak, 1995). For digits forward, participants were asked to repeat number sequences that were read aloud at a rate of one number per second. For digits backward, participants were asked to repeat number sequences in a backward fashion. The test consisted of pairs of sequences within items of increasing difficulty. The first item contained two number sequences. The task ended when either the participant failed to repeat two pairs of number sequences or successfully repeated all number sequences. The spatial span forward and backwards was similar to the digit span procedure. However, the sequence to be recalled was a series of positions of blocks pointed to by the examiner. The blocks were arranged in a spatial configuration.

Verbal fluency. Since many studies have shown schizophrenics to be impaired in verbal fluency, performance on the FAS was assessed (Lezak, 1995). Also, ketamine has been shown to disrupt verbal fluency performance (Krystal et al, 1994; Adler et al, 1998). For this task, participants were asked in three trials to generate as many words as possible in $60 \mathrm{~s}$ that started with the letters ' $\mathrm{F}$ ', ' $\mathrm{A}$ ', and ' $\mathrm{S}$ ', respectively.

\section{Data Analyses}

Behavioral ratings and cognitive measures were analyzed between conditions (placebo $v s$ ketamine) with paired $t$ tests. The virtual Morris task data were analyzed with a 2 (drug) $\times 5$ (block) repeated measures ANOVAs, and paired $t$-tests for the probe trial. One-tailed tests were used for the learning and memory variables because of the directional hypotheses, whereas two-tailed tests were used for the other variables. The relationships between cognitive and behavior measures where computed with the Pearson productmoment correlations. Adjustments of the critical significance level for multiple comparisons were not made due to the preliminary nature of this study. Analyses were conducted with the Statistical Package for Social Sciences (SPSS) version 11.0 software package.

\section{RESULTS}

\section{Behavioral Ratings}

Participants experienced schizophrenia-like features associated with ketamine administration as exhibited by an increase in behavioral rating scores. They showed an increase in behavioral rating scores (SANS: $t=2.5, \mathrm{df}=9$, $p<0.05$; CADSS: $t=4.6, \quad \mathrm{df}=9, \quad p<0.001$; $\quad$ BPRS: $t=1.7, \mathrm{df}=9, p=0.1)$. Means and $\mathrm{SD}$ are presented in Table 1. Typical reactions reported were visual alterations (colors, texture exaggerated), auditory alterations (sounds

Table I Means (SD) for Behavioral Rating Scales

\begin{tabular}{lcc}
\hline Behavioral scale & Placebo & Ketamine \\
\hline SANS & $3.0(2.1)$ & $6.6(3.4)^{*}$ \\
CADSS & $0.4(0.8)$ & $18(12.0)^{*}$ \\
BPRS & $21.0(8.2)$ & $25.4(8.2)^{* * *}$ \\
\hline
\end{tabular}

$* p \leqslant 0.05 ;{ }^{*} * p=0.12$. 
intensified), altered time perception (time went by very quickly or slowly), being in a dreamlike state, things moving in slow motion, and body distortions. Decreased facial expression and decreased willingness to engage in conversation were also noted. The intensity of reaction varied among participants.

No subject reported adverse effects or recreational ketamine-like substance use during follow-up phone contact.

\section{COGNITIVE MEASURES}

\section{Learning and Memory}

Virtual Morris water task. Eight participants completed this task for both experimental sessions. One participant had to abort testing due to feelings of motion sickness and another failed to begin testing due to nausea resulting from the ketamine. Measures of acquisition were latency and distance to swim to the platform for five blocks of four trials, and percent distance traveled in platform quadrant for the probe trial that immediately followed the last block. Distance traveled and latency to the platform were analyzed with 2 (drug) $\times 5$ (block) repeated measures ANOVAs. For distance, a significant drug by block interaction $(\mathrm{F}(4$, $24)=3.6, p=0.01)$ and a significant main effect for block $(\mathrm{F}(4,24)=7.4, p=0.001)$ were found, but, there was no significant main effect of drug $\mathrm{F}(4,24)=1.04, p=0.174$. Follow-up pairwise comparisons revealed a significant difference for Block $1 t(7)=2.0, p=0.045$, such that when subjects were administered ketamine they traveled more distance to reach the platform compared to when given placebo (Figure 2). Pairwise comparisons for Blocks 2-5 were not statistically significant. Results were similar for latency to find the platform. A graphical display of mean distance traveled to platform by drug condition is displayed in Figure 2. Results revealed no statistically significant difference between ketamine and placebo for percent distance in platform quadrant for the probe trial. As expected, there was no statistically significant difference

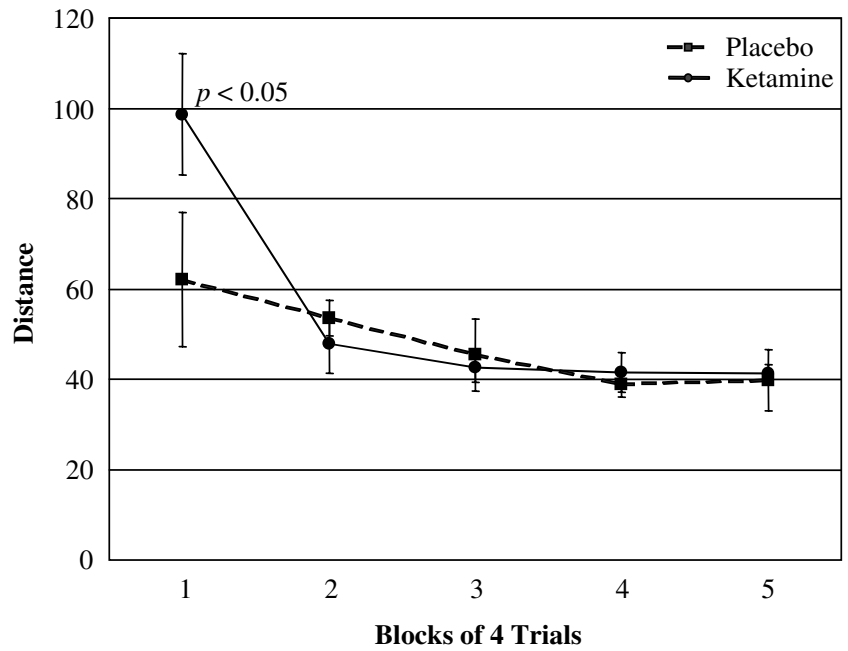

Figure 2 Acquisition task: mean distance traveled to hidden platform by drug group. between ketamine and placebo conditions in latency to visible platform for Block $1(t(7)=0.67, p=0.53$ or Block 2 $(t(7)=0.98, p=0.36$.

Retrieval memory for the task learned prior to experimental sessions was measured by the percent distance traveled in the platform quadrant for a probe trial. As predicted, there was no significant difference between ketamine and placebo conditions for percent distance traveled $(t(7)=0.26, p=0.8)$.

Hopkins verbal learning test. Nine subjects completed this task under both drug conditions. Consistent with the hypothesis, subjects administered ketamine were impaired in encoding new words when compared to placebo $(t(8)=2.0, p=0.0425)$. The effect size for this difference was moderate to large (Cohen's $d=0.77$ ). Delayed recall of the new word list revealed similar impairment for the ketamine condition $(t(8)=2.1, \quad p=0.0365)$; Cohen's $d=0.85$ ). Also consistent with hypothesis, when subjects were asked to recall words from a list learned prior to the experimental sessions, there was no difference among the ketamine and placebo conditions. Means and standard deviations are presented in Table 2.

\section{Attention}

Nine participants completed the modified Stroop task under both drug conditions. Participants under the influence of ketamine had lower scores on all conditions of this task. However, results revealed no significant difference between ketamine and placebo conditions for color-word interference. Means and standard deviations are presented in Table 2.

Table 2 Means, Standard Deviations (SD), Statistical Significance $(p)$, and Effect Size (d) Values for Selective Attention, Working Memory, and Verbal Fluency Performance

\begin{tabular}{|c|c|c|c|}
\hline Cognitive task & Placebo & Ketamine & $p$, $d$ values \\
\hline \multicolumn{4}{|l|}{ HVLT } \\
\hline Recall (old list) & $11.4(1.0)$ & II.4 (0.9) & $0.99,0$ \\
\hline Encode (new list) & $31.1(4.2)$ & $28.0(3.9)^{*}$ & $0.043,0.77$ \\
\hline Delayed recall (new list) & $10.8(1.3)$ & $9.7(1.3)^{*}$ & $0.037,0.85$ \\
\hline \multicolumn{4}{|l|}{ Stroop } \\
\hline Color-word interference & $5.4(8.9)$ & $3.6(6.9)$ & $0.5,0.23$ \\
\hline \multicolumn{4}{|l|}{ Digit span } \\
\hline Forward & $\mid 2.1(2.2)$ & $12.3(3.1)$ & $0.6,0.08$ \\
\hline Backward & $8.2(2.6)$ & $8.4(3.0)$ & $0.7,0.07$ \\
\hline \multicolumn{4}{|l|}{ Spatial span } \\
\hline Forward & $9.7(1.6)$ & $8.9(2.2)$ & $0.4,0.42$ \\
\hline Backward & $9.0(1.1)$ & $8.0(1.6)$ & $0.15,0.74$ \\
\hline FAS (total) & $48.8(14.1)$ & $45.7(13.2)$ & $0.23,0.23$ \\
\hline
\end{tabular}

$* p<0.05$. 


\section{Working Memory}

Nine participants completed both digit and spatial spans forward and backward. There were no obvious impairments as illustrated by mean values and statistical tests in digit span forward and backward associated with ketamine administration. However, mean values for spatial span, both forward and backward, were lower for the ketamine compared to the placebo condition, although these differences were not statistically significant. Means and standard deviations are presented in Table 2.

\section{Verbal Fluency}

Nine participants completed the FAS task. Examination of total FAS mean scores revealed that subjects administered ketamine produced fewer words. However, this difference was not statistically significant. Means and standard deviations are presented in Table 2.

\section{Behavioral and Cognitive Relationships}

Consistent with hypotheses, there was a negative significant correlation between encoding new words on the HVLT and measures on the SANS $(r(8)=-0.698, p=0.018)$ and BPRS $(r(8)=-0.64, \quad p=0.031)$, but not on the CADSS $(r(8)=-0.386, p=0.152)$. Delayed recall of words on the HVLT was also significantly negatively correlated with measures on the SANS $(r(8)=-0.7, p=0.018)$ and BPRS $(r(8)=-0.637, \quad p=0.032)$, but not the CADSS $(r(8)=-0.289, p=0.225)$. Retrieval of already learned words on the HVLT was significantly related to BPRS scores $(r(8)=-0.643, p=0.043)$, but not to the SANS $(r(8)=-0.274, p=0.24)$ or CADSS $(r(8)=-0.5, p=0.085)$. For the Morris water task, only percent distance spent in the target quadrant for the probe trial of the maze previously acquired was negatively related to BPRS $(r(7)=-0.744$, $p=0.017)$ and CADSS $(r(7)=-0.71, p=0.025)$ measures. Behavioral measures were not significantly related to performance on other cognitive measures.

\section{DISCUSSION}

The purpose of this study was to investigate whether ketamine differentially impairs encoding and retrieval of spatial $v s$ nonspatial declarative information in healthy humans. To our knowledge, no other studies have specifically addressed the effects of NMDAR antagonism on encoding $v s$ retrieval in both spatial and nonspatial domains in humans. Consistent with our hypotheses, ketamine disrupted learning of new verbal information as exhibited by a significant decrease in HVLT scores. Correspondingly, as predicted, ketamine did not disrupt retrieval of verbal information learned prior to drug administration. These findings replicate a study by Hetem et al (2000) that showed ketamine to disrupt learning of new words but not retrieval of previously learned words. They are also consistent with studies showing ketamine to impair verbal memory (Krystal et al, 1994; Malhotra et al, 1996). The results are also in accordance with previous human research showing ketamine to impair encoding of new rulebased information (ie WCST), but not retrieval if this rule was learned previously (Krystal et al, 2000). Similarly, some researchers suggest that learning and memory are particularly impaired in schizophrenia, even when accounting for possible underlying cognitive deficits such as attention and working memory (Holthausen et al, 2003; Saykin et al, 1991, 1994).

The animal research is rich in establishing evidence that NMDAR antagonism impairs acquisition by disrupting hippocampal LTP, which is often viewed as being one of the mechanisms for memory storage within the brain (for a review, see Morris and Davis, 1994). Classically, hippocampal function is assessed in nonhumans by the Morris water maze, a test of spatial learning and memory (Morris, 1981). NMDAR antagonism has been shown to specifically impair spatial learning but not retrieval of this task in rats (Kant et al, 1991; McLamb et al, 1990). Interestingly, knockout mice for the NMDAR1 subunit in the CA1 of the hippocampus exhibit deficits in spatial learning of this task (Tsien et al, 1996). In our current study, a virtual version of the Morris water task was utilized, and results show that ketamine exposure did not impair retrieval; this is consistent with our hypotheses and with results from rat studies. However, ketamine did disrupt acquisition on this task as revealed by greater distance traveled and longer escape latencies, but this effect was only evident on the first learning block of the task. The differences in acquisition between ketamine and placebo conditions cannot be attributed to sensory, motor, or attention factors since performance on the visible platform condition was comparable. These data dovetail well with schizophrenia because it has been shown that people with schizophrenia show impairments in this task, perhaps due to NMDAR dysfunction (Astur et al, 2003).

To our knowledge, this is the first study to assess the differential effects of NMDAR antagonism on spatial acquisition and retrieval in humans. Although a significant difference for the acquisition of the virtual Morris water task between ketamine and placebo conditions did not extend throughout the task, this does not preclude the fact that NMDARs are important for learning. In a review by Nakazawa et al (2004), substantial evidence implicates NMDARs, specifically within the hippocampal area CA3, to be essential in the early stages of learning but not always in the later stages of learning. Thus, NMDARs appear to be crucial for the rapid encoding of information, such as that found in one-trial learning. Furthermore, pretraining on the Morris water maze greatly diminishes the impairment effect of NMDAR antagonists in rodents (Bannerman et al, 1995; Saucier and Cain, 1995). Thus, our data suggest that NMDAR antagonism disrupt the early stage of learning, as demonstrated by the impaired performance on the first acquisition block of the virtual Morris water task. This issue may best be addressed by using a modified version of the Morris water task (eg delayed matching-to-place, for a review, see Nakazawa et al, 2004) that has been demonstrated to be more sensitive to NMDAR antagonism.

While ketamine did not significantly impair performance on working memory, selective attention, or verbal fluency tasks in this study, some trends existed that would suggest significant results in a larger sample size. This is not particularly remarkable because prior studies assessing the effects of ketamine on these cognitive processes have had 
mixed results. Some studies have found ketamine to disrupt working memory on N-back tasks (Morgan et al, 2004; Adler et al, 1998) and backward digit span task (Honey et al, 2003), while others found no significant impairment on a spatial working memory task (Newcomer et al, 1999), or forward and backward digit spans (Ghoneim et al, 1985). Impaired verbal fluency with ketamine administration has been shown in some studies (Adler et al, 1998; Krystal et al, 1994, 1998) but not others (Krystal et al, 1999; Newcomer et al, 1999). Some studies have shown ketamine to impair performance on tasks of sustained attention (Krystal et al, 1994), while others have not (Krystal et al, 2000; Newcomer et al, 1999). Consistent with this study, many have shown ketamine not to impair performance on tasks of selective attention (Harborne et al, 1996; Newcomer et al, 1999; Oranje et al, 2000). These conflicting findings are likely due to methodological differences, such as ketamine dose, route of administration (ie bolus $v s$ infusion), task differences, and the time when tasks were performed during ketamine administration (ie prior, during, or following steady-state levels). For example, the studies that found such impairments used higher doses (Adler et al, 1998; Honey et al, 2003; Krystal et al, 1994, 1998, 1999, 2000; Morgan et al, 2004), and different administration procedures (ie a bolus followed by a maintenance infusion (Adler et al, 1998; Honey et al, 2003; Krystal et al, 1998, 1999, 2000)) when compared to this study. It is likely that working memory, attention, and verbal fluency processes are impaired at higher doses, which would be more compatible with that observed in schizophrenia (Heinrichs and Zakzanis, 1998). However, our findings are consistent with the one study that used similar procedures (Newcomer et al, 1999).

Learning and memory impairments in schizophrenia may be related to hippocampal NMDAR abnormalities observed in schizophrenia (Gao et al, 2000; Harrison et al, 2003). Our results suggest such an association. Significant correlations were found between behavioral ratings and learning and memory variables. The severity of schizophrenia-like symptoms was directly related to poor information encoding. The severity of schizophrenia-like features was not significantly related to performance on selective attention, working memory, or verbal fluency tasks. The majority of studies on the effects of ketamine on cognition fail to report whether the relationship between cognitive performance and symptom ratings was investigated. However, one study found no significant relationship between BPRS measures and performance on word recognition and recall (Malhotra et al, 1996), whereas another found a relationship between measures on a thought disorder scale and working memory performance (Adler et al, 1998). Whether there is one common neural circuit or an interaction of distributed neural networks involved in ketamine-induced symptoms and learning deficits remain to be determined. Functional neuroimaging studies may help elucidate this issue.

There are several limitations of this study. First, the sample size is small. Data must be acquired on more subjects to substantiate these preliminary findings. Spatial working memory deficits with ketamine administration may prove to be statistically significant with a larger subject number since the effect sizes were of medium magnitude. It is possible that ketamine may disrupt spatial processing in general. Second, only one ketamine dose was administered.
It is plausible that working memory, selective attention, and verbal fluency deficits previously reported in some ketamine studies are dose dependent.

This study attempted to determine the impact of NMDAR antagonism on several cognitive processes in healthy humans. Results of this study provide further evidence for a differential effect of NMDAR blockade on acquisition $v s$ retrieval of verbal and spatial information with the particular dose of ketamine administered in this study. A unique aspect of this study was the utilization of a hippocampal-dependent task in an attempt to bridge the gap between nonhuman animal and human NMDAR antagonism research.

\section{ACKNOWLEDGEMENTS}

This study was supported by the Cellular and Integrative Neuroscience Training Grant to the University of Maryland, NIH NS07375, a Young Investigator Award from the National Alliance for Research in Schizophrenia and Depression (NARSAD) to John Lauriello, and by the Mental Illness and Neuroscience Discovery (MIND) Institute. This study would not be possible without the contributions of Ranee Barrow, Elma Landgraf, Rhoshel Lenroot, and Paul Mullins. We are also grateful to Adrienne Lahti for consulting on ketamine-challenge research and Henry Holcomb for valuable comments.

\section{REFERENCES}

Adler CM, Goldberg TE, Malhotra AK, Pickar D, Breier A. (1998). Effects of ketamine on thought disorder, working memory, and semantic memory in healthy volunteers. Biol Psychiatry 43: 811-816.

Andreasen NC (1984). The Scale for the Assessment of Negative Symptoms. University of Iowa: Iowa City.

Astur RS, Mathalon DH, D'Souza DC, Krystal JH, St. Germain S, Constable RT et al (2003). Using virtual reality to examine hippocampus functioning in schizophrenia. International Workshop on Virtual Rehabilitation Proceedings; September 21-22; Rutgers University, Piscataway, NJ.

Astur RS, Ortiz ML, Sutherland RJ (1998). A characterization of performance by men and women in a virtual Morris water task: a large and reliable sex difference. Behav Brain Res 93: 185-190.

Astur RS, Taylor LB, Mamelak AN, Philpott L, Sutherland RJ (2002). Human with hippocampus damage display severe spatial memory impairments in a virtual morris water task. Behav Brain Res 132: 77-84.

Bannerman DM, Good MA, Butcher SP, Ramsay M, Morris RGM (1995). Distinct components of spatial learning revealed by prior training and NMDA receptor blockade. Nature 378: 182-186.

Bremner JD, Krystal JH, Putnam FW, Southwick SM, Marmar C, Charney DS et al (1998). Measurement of dissociative states with the Clinician-Administered Dissociative States Scale (CADSS). J Trauma Stress 11: 125-136.

Coyle JT, Tsai G, Goff D (2003). Converging evidence of NMDA receptor hypofunction in the pathophysiology of schizophrenia. Ann NY Acad Sci 1003: 318-327.

First MB, Spitzer RL, Gibbon M, Williams JBW (1995). Structured Clinical Interview for DSM-IV Axis I Disorders, Non-Patient Edition (SCID-NP), version 2. New York State Psychiatric Institute, Biometrics Research: New York. 
Gao XM, Sakai K, Roberts RC, Conley RR, Dean B, Tamminga CA (2000). Ionotropic glutamate receptors and expression of $\mathrm{N}$-methyl-D-aspartate receptor subunits in subregions of human hippocampus: effects of schizophrenia. Am J Psychiatry 157: 1141-1149.

Ghoneim M, Hinrichs JV, Mewaldt SP, Peterson RC (1985). Ketamine: behavioural effects at subanesthetic doses. J Clin Psychopharmacol 5: 70-77.

Hamilton DA, Driscoll I, Sutherland RJ (2002). Human place learning in a virtual Morris water task: some important constraints on the flexibility of place navigation. Behav Brain Res 129: 159-170.

Harborne GC, Watson FL, Healy DT, Groves L (1996). The effects of sub-anaesthetic doses of ketamine on memory, cognitive performance and subjective experience in healthy volunteers. J Psychopharmacol 10: 134-140.

Harrison PJ, Law AJ, Eastwod SL (2003). Glutamate receptors and transporters in the hippocampus in schizophrenia. Ann NY Acad Sci 1003: 94-101.

Heinrichs RW, Zakzanis KK (1998). Neurocognitive deficit in schizophrenia: a quantitative review of the evidence. Neuropsychology 12: 426-445.

Hetem LAB, Danion JM, Diemunsch P, Brandt C (2000). Effect of a subanesthetic dose of ketamine on memory and conscious awareness in healthy volunteers. Psychopharmacology 152: 283-288.

Holthausen EAE, Wiersma D, Sitskoorn MM, Dingemans PM, Schene AH, Bosch RJ (2003). Long-term memory deficits in schizophrenia: primary or secondary dysfunction? Neuropsychology 17: 539-547.

Honey RAE, Turner DC, Honey GD, Sharar SR, Kumaran D, Pomarol-Clotet E et al (2003). Subdissociative dose ketamine produces a deficit in manipulation but not maintenance of the contents of working memory. Neuropsychopharmacology 28: 2037-2044.

Kant GJ, Wright WL, Robinson III TN, D’Angelo CP (1991). Effects of MK-801 on learning and memory as assessed using a novel water task. Pharmacol Biochem Behav 39: 479-485.

Krystal JH, Bennett A, Abi-Saab D, Belger A, Karper LP, D’Souza DC et al (2000). Dissociation of ketamine effects on rule acquisition and rule implementation: possible relevance to NMDA receptor contributions to executive cognitive functions. Biol Psychiatry 47: 137-143.

Krystal JH, D'Souza DC, Karper LP, Bennett A, Abi-Dargham A, Abi-Saab D et al (1999). Interactive effects of subanesthetic ketamine and haloperidol. Psychopharmacology 145: 193-204.

Krystal JH, D’Souza DC, Mathalon D, Belger PE, Hoffman R (2003). NMDA receptor antagonist effects, cortical glutamatergic function, and schizophrenia: toward a paradigm shift in medication development. Psychopharmacology 169: 215-233.

Krystal JH, Karper LP, Bennett A, D'Souza DC, Abi-Dargham A, Morrisey $\mathrm{K}$ et al (1998). Interactive effects of subanesthetic ketamine and subhypnotic lorazepam in humans. Psychopharmacology 135: 213-299.

Krystal JH, Karper LP, Seibyl JP, Freeman GK, Delaney R, Bremner JD et al (1994). Subanesthetic effects of the noncompetitive NMDA antagonist, ketamine, in humans. Psychotomimetic, perceptual, cognitive, and neuroendocrine responses. Arch Gen Psychiatry 51: 199-214.

Lahti AC, Holcomb HH, Medoff DR, Tamminga CA (1995a). Ketamine activated psychosis and alters limbic flow in schizophrenia. NeuroReport 6: 869-872.
Lahti AC, Koffel B, LaPorte D, Tamminga CA (1995b). Subanesthetic doses of ketamine stimulate psychosis in schizophrenia. Neuropsychopharmacology 13: 9-19.

Lezak MD (1995). Neuropsychological Assessment. Oxford University Press: New York.

Malhotra AK, Pinals DA, Adler CM, Elman I, Clifton A, Pickar D et al (1997). Ketamine-induced exacerbation of psychotic symptoms and cognitive impairment in neuroleptic-free schizophrenics. Neuropsychopharmacology 17: 141-150.

Malhotra AK, Pinals DA, Weingartner H, Sirocco K, Missar CD, Pickar D et al (1996). NMDA receptor function and human cognition: the effects of ketamine in healthy volunteers. Neuropsychopharmacology 14: 301-307.

McLamb RL, Williams LR, Nanry KP, Wilson WA, Tilson HA (1990). MK-801 impedes the acquisition of a spatial memory task in rats. Pharmacol Biochem Behav 37: 41-45.

Morgan CJA, Mofeez A, Brandner B, Bromley L, Curran HV (2004). Acute effects of ketamine on memory systems and psychotic symptoms in healthy volunteers. Neuropsychopharmacology 29: 208-218.

Morris RGM (1981). Spatial localization does not require the presence of local cues. Learn Motiv 12: 239-269.

Morris RGM, Davis M (1994). The role of NMDA receptors in learning and memory. In: Collingridge GL, Watkins JC (eds). The NMDA Receptor, 2nd edn. Oxford University Press: New York.

Nakazawa K, McHugh TJ, Wilson MA, Tonegawa S (2004). NMDA receptors, place cells, and hippocampal spatial memory. Nat Rev Neurosci 5: 361-372.

Newcomer JW, Farber NB, Jevtovic-Todorovic V, Selke G, Melson AK, Hershey T et al (1999). Ketamine-induced NMDA receptor hypofunction as a model of memory impairment and psychosis. Neuropsychopharmacology 20: 106-118.

Newcomer JW, Krystal JH (2001). NMDA receptor regulation of memory and behavior in humans. Hippocampus 11: 529-542.

Olney JW, Farber NB (1995). Glutamate receptor dysfunction in schizophrenia. Arch Gen Psychiatry 52: 998-1007.

Oranje B, van Berckel BNM, Kemner C, van Ree JM, Kahn RS, Verbaten MN (2000). The effects of a sub-anaesthetic dose of ketamine on human selective attention. Neuropsychopharmacology 22: 293-302.

Overall JF, Gorham DR (1962). The brief psychiatric rating scale. Psychol Rep 10: 799-812.

Rowland LM, Bustillo JR, Mullins PGM, Jung RE, Lenroot R, Landgraf $\mathrm{E}$ et al (2005). The effects of ketamine on anterior cingulate glutamate metabolism in healthy humans: a $4.0-\mathrm{T}$ Proton MRS Study. Am J Psychaitry 162 (in press).

Sandstrom NJ, Kaufman J, Huettel SA (1998). Males and females use different distal cues in a virtual environment navigation task. Brain Res Cogn Brain Res 6: 351-360.

Saucier D, Cain DP (1995). Spatial learning without NMDA receptor-dependent long-term potentiation. Nature 378: 186-189.

Saykin AJ, Gur RC, Gur RE, Mozley PD, Mozley LH, Resnick SM et al (1991). Neuropsychological function in schizophrenia. Selective impairment in memory and learning. Arch Gen Psychiatry 48: 618-624.

Saykin AJ, Shtasel DL, Gur RE, Kester DB, Mozley LH, Stafiniak P et al (1994). Neuropsychological deficits in neuroleptic naïve patients with first-episode schizophrenia. Arch Gen Psychiatry 51: 124-131.

Tsien JZ, Heurta PT, Tonegawa S (1996). The essential role of hippocampal CA1 NMDA receptor-dependent synaptic plasticity in spatial memory. Cell 87: 1327-1338. 